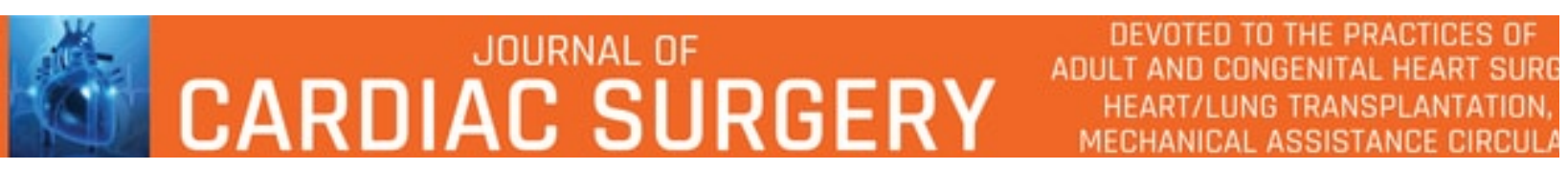

\title{
The Epicenter of Change: Robotic Cardiac Surgery As A Career Choice
}

\begin{tabular}{|r|l|}
\hline Journal: & Journal of Cardiac Surgery \\
\hline Manuscript ID & Draft \\
\hline Manuscript Type: & Editorial \\
\hline Author: & n/a \\
\hline Complete List of Authors: & $\begin{array}{l}\text { Torregrossa, Gianluca; University of Chicago Pritzker School of Medicine } \\
\text { Amabile, Andrea; Yale University School of Medicine, Cardiac Surgery } \\
\text { Oosterlinck, Wouter; KU Leuven University Hospitals Leuven, } \\
\text { Cardiovascular Diseases } \\
\text { Van den Eynde, Jef } \\
\text { Mori, Makoto; Yale University School of Medicine, Section of Cardiac } \\
\text { Surgery } \\
\text { Geirsson, Arnar; Yale University School of Medicine, Cardiac Surgery } \\
\text { Balkhy, Husam; University of Chicago, Cardiothoracic Surgery; Husam } \\
\text { Balkhy }\end{array}$ \\
\hline Keywords: & robotics, education \\
\hline &
\end{tabular}


The Epicenter of Change: Robotic Cardiac Surgery As A Career Choice

Gianluca Torregrossa, $\mathrm{MD}^{1 *}$; Andrea Amabile, $\mathrm{MD}^{2 *}$; Wouter Oosterlinck, $\mathrm{MD}, \mathrm{PhD}^{3}$; Jef Van den Eynde, BSc ${ }^{3}$; Makoto Mori, MD²; Arnar Geirsson, $\mathrm{MD}^{2}$;

Husam H. Balkhy, MD ${ }^{1}$

1- Division of Minimally Invasive and Robotic Cardiac Surgery, Department of Surgery, University of Chicago Medicine (Chicago, IL)

2- Division of Cardiac Surgery, Department of Surgery, Yale School of Medicine (New Haven, CT)

3- Department of Cardiovascular Diseases, University Hospitals Leuven (Leuven, Belgium)

17 *These Authors contributed equally to this work.

Dr. Gianluca Torregrossa, MD

Division of Minimally Invasive and Robotic Cardiac Surgery 5758 S.Maryland Ave, Chicago, IL 60637,USA.

24 Conflict of Interest: HHB: Proctor for Intuitive.

25 Article word count: 1888 


\section{Abstract}

Building up a career in robotic cardiac surgery can be challenging and requires a broad

28 variety of hard and soft skills. Many pathways can be taken to achieve the same goal, but a 29 standardized training curriculum in robotic cardiac surgery is necessary and should be 30 demanded by the surgical community. In addition to developing technical skills, trainees 31 interested in devoting their career to the evolving field of robotic cardiac surgery could benefit 32 from incorporating enhanced soft and mental skills in their lifestyle. 


\section{1 \\ Introduction}

"Medicine is no profession for the status quo. Cardiac Surgery is no exception. In fact,

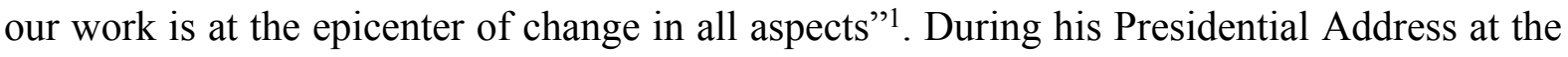
eighty-fifth Annual Meeting of the American Association for Thoracic Surgery (AATS), Dr.

Tirone David provided a spectacular overview on the dramatic changes facing the field of cardiac surgery, emphasizing the fact that surgeons should never forget that change is inevitable and that therefore they must embrace change with a positive mindset, adapting to it quickly and enjoying it.

The development of robotic surgical platforms has indeed paved the way for a new

60 reality in our field. Following the first successful robotic-assisted mitral valve procedure ${ }^{2}$ and

61 robotic-assisted coronary artery bypass ${ }^{3}$ more than twenty years ago, the robotic approach has been adopted in a growing number of institutions around the world ${ }^{4}$. Although these two procedures continue to make up the majority of robotic cardiac cases, the feasibility and safety of a totally robotic approach has been demonstrated in a broad variety of other situations ${ }^{5}$. 65 Since robotic-assisted totally endoscopic surgery requires a specific skillset, there is an 66 increasing demand for structured and standardized training pathways aiming at preparing the next generation of robotic cardiac surgeons. This Editorial aims at discussing those skills which we believe are imperative to building a successful career in robotic cardiac surgery (Figure 1).

\section{On hard skills development: dedicated training curricula}

71 Aspiring robotic cardiac surgeons should learn cardiac surgery first. As plain as it may sound, it is not possible to provide optimal quality of care via the robotic platform without having previously mastered open skills (and core concepts) in cardiac surgery. Gradually,

74 trainees who become interested in the field should start increasing their exposure by shadowing faculty members who routinely perform their cases minimally invasively or robotically, if 
76 possible. Once the interest becomes predominant, they should look for a more structured

training pathway. At the present time, consistent exposure to robotic cardiac surgery is not widely included in cardiac surgery training curricula, and a minimum case log of robotic cardiac procedures has not been adopted as a requirement for board certification. Consequently, young cardiac surgeons with an interest in pursuing a career in robotics can generally follow one of two major pathways: via industry support, or independently from industry.

In the former pathway, preclinical training can be initiated for residents, fellows or junior faculty using the da Vinci ${ }^{\circledR}$ System (Intuitive Surgical, Sunnyvale, CA) in dry- and wetlab courses. Besides its headquarters in Sunnyvale as well as the training facilities in Atlanta (Atlanta, GA, USA) and Houston (Houston, TX, USA), Intuitive has recently founded several robotic training centers outside the United States, such as IRCAD 2 (Strasbourg, France), RAIN (Naples, Italy), RPA (Sydney, Australia), and IRCS-World Laparoscopy Hospital (New Delhi, India). After an online video-based course, candidates receive hands-on training at the surgical console. After having completed a set of requirements, candidates obtain the da Vinci ${ }^{\circledR}$ System Training Certificate, which helps demonstrate their experience to employers and hospitals. The eligibility criteria for this achievement are listed in Table 1.

In the latter pathway, aspiring robotic cardiac surgeons must apply for a position in a center which itself can provide simulator and other pre-clinical training facilities, including dry- and wet-labs. Both pathways converge when the surgeon's skillset has been built, and clinical training can be initiated. During this phase, guidance by expert robotic surgeons is mandatory. If not available at their own center, trainees should visit experienced centers to receive advanced training. For the established young surgeon looking to begin a robotic cardiac program and after completing the above preliminary steps, involving the entire team is crucial: a dedicated robotic training should be offered not only to surgeons, but also to the tableside assistant, scrub nurses, anesthesia and perfusion teams. Consistency in the team of people 
101 trained to work together during a robotic procedure is another important prerequisite to 102 building a successful robotic cardiac program.

103 Dedicated robotic cardiac surgery fellowships and courses are also currently available 104 at an increasing number of institutions (Table 2). Nevertheless, no clearly outlined career track 105 has been established and the opportunities remain hard to find. The current lack of standardized 106 training poses several challenges. First, the current training model largely relies on the 107 availability of mentors who are motivated to guide young surgeons through their first robotic 108 experiences. The number of mentors is limited due to the limited number of institutions 109 routinely providing robotic-assisted cardiac surgical care, and this likely represents an obstacle 110 to the large-scale development of the field of robotic cardiac surgery at current times. In 111 addition, the quality of performances of neither the mentee nor the mentor is monitored by a 112 central organization, which should be a necessary prerequisite to ensure equal and diffuse

113 education. Finally, important financial constraints may be posed by the perceived high cost of 114 robotic systems, simulators, dry- and wet-lab facilities in case these have to be bought ex novo 115 by individual hospitals in the absence of dedicated subsidies. However, Coyan et al. have 116 recently demonstrated that initiating a robotic program can be cost-neutral as well as maintains 117 integrity in clinical outcomes ${ }^{6}$.

On hard skills development: besides the robotic console

120 Even after reaching a satisfying confidence with the robotic console, it is essential to 121 keep training on simulators in order to enhance technical dexterity and boost visual feedback 122 perception, thus strengthening one's confidence further. Robotic cardiac surgeons at any stage 123 of their training may also find it useful to shadow robotic colleagues from different specialties. 124 Spending time in different operating rooms may help in grasping core concepts at a deeper 125 level and give birth to new ideas on how to solve technical issues in the field of interest. 
In addition to that, young robotic cardiac surgeons may want to build a detailed video-

127 library of personal cases to be reviewed on a regular basis, which can be used to reinforce the

128 memory of technical steps at earlier career stages and to teach trainees at later career stages, in

129 addition to troubleshooting any complications which may occur.

130 Nonetheless, it is also mandatory to preserve open skills in order to maintain a busy

131 surgical practice and to be ready in the management of any undesirable robotic complications

132 requiring conversion. Therefore, even if the young surgeon is interested in committing to a

133 fully robotic cardiac practice, continuing to take call and dealing with general cardiac

134 emergencies will be necessary to maintain critical open surgical skills. Another effective way

135 to maintain open skills is to continue to teach younger trainees in wet-lab settings on a regular

136 basis (e.g., weekly wet-labs on coronary anastomosis performed on animal models).

On soft skill development: the mentor-mentee relationship

139 As physicians and surgeons, our career is built up through a constellation of people we have

140 the fortune to find along our journey - role models who are at the same time knowledgeable, 141 approachable and trustworthy. These people act as teachers, mentors, and coaches and they not 142 only care about our patient management ability and technical skills development, but also 143 provide insightful suggestions and help with career paths, personal development, networking, 144 research projects and job openings. The mentor-mentee relationship must be nurtured, 145 respected and based on open communication and mutual trust. Mentors tend to guide mentees 146 in many aspects of their lives that are not just career-related, and it is not uncommon for 147 mentors and mentees to share similar background interests which contribute to solidifying the 148 relationship. As a consequence of this, a successful mentor-mentee relationship is also the 149 mentee's responsibility - who must generate enthusiasm in the mentor, inspire reliability, and 150 show a steady willingness to improve and learn with dedication. 
On soft skill development: mental skills training

153 Developing a strong set of mental skills in the early stages of training has several

154 positive effects on the quality of care provided, on career advancement, and on physical and

155 mental health. As recently discussed by Spoon et al., mental skills training has been shown to

156 enhance surgical performance and to reduce operator stress and burn-out ${ }^{7}$.

157 We recommended that residency and fellowship programs apply existing models of mental

158 training with the aim of incorporating (at least) six essential mental skills in the personal and

159 professional growth of their trainees: mental toughness (i.e., the ability to thrive in demanding

160 situations), arousal (the minimal level of anxiety necessary to achieve assigned tasks in

161 stressful situations), attention focus (the ability to concentrate attention on a specific stimulus

162 in order to optimize the performance), visualization (the ability to picture oneself performing

163 the task prior to the event), internal monologue (the ability to maintain positive thoughts during

164 stressful events and mistakes) and cohesion (the strength of interpersonal connection amongst

165 team members in reaching a common goal). Combining these attributes in approaching new

166 challenges can facilitate maintaining a positive and confident approach in training. The ability

167 to communicate in a clear and open way between the surgeon and the team is also crucial.

168 Another interesting perspective was recently proposed by Maddaus, who formulated

169 the "Resilience Bank Account" strategy for optimizing performances in high-stress

170 environments such as the daily cardiac surgery practice and training ${ }^{8}$. He compared developing

171 and maintaining specific daily habits (i.e., sleep, exercise, meditation, gratitude, self-

172 compassion and connection) to the process of making daily small deposits of money into one's

173 bank account. Instead of impacting on one's personal finances, deposits made by practicing

174 these habits end up strengthening one's resilience, thus improving physical and mental health,

175 self-regulation and flexibility over time. 
176 Flexibility is indeed an essential characteristic that young robotic cardiac surgeons must

177 possess and safeguard, since they embraced a field in continuous development.

178 In the aforementioned AATS Presidential Address, Dr. David concluded stating that "[Future

179 surgeons] will be the ones who will develop new therapeutic approaches to treat patients with

180 cardiothoracic diseases. They will be making the changes in our specialty. Change is good.

181 Change is necessary. Change is progress". Undeniably, surgeons interested in devoting their

182 career to robotic cardiac surgery must be ready to change quickly, take on new challenges, and

183 embrace the process itself, sustained by their passion and their desire to ultimately benefit the

184 most important person in this equation: the patient.

185

186

187

188

189

190

191

192

193

194

195

196

197

198

199

200 
201 Table 1

202 Criteria for the Certificate of da Vinci® System Training for Residents and Fellows 203

204 Table 2

205 Currently available robotic fellowships and specialization courses.

206 Accessed July $18^{\text {th }}, 2021$

207

208 Figure 1

209 Tips to building a successful career in robotic cardiac surgery.

210

211

212

213

214

215

216

217

218

219

220

221

222

223

224

225 


\section{References}

227 1. David TE. J Thorac Cardiovasc Surg. 2005;130(4):961-965.

228 2. Carpentier A, et al. C R Acad Sci III. 1998;321(5):437-442.

229 3. Mohr FW, et al. J Thorac Cardiovasc Surg. 1999;117(6):1212-1214.

230 4. Yanagawa F, et al. JAMA Surg. 2015;150(8):771-777.

$231 \quad$ 5. Balkhy HH, et al. Innovations (Phila). 2020;15(3):187-194.

232 6. Coyan G, et al. J Thorac Cardiovasc Surg. 2018;156(3):1040-1047.

233 7. Spoon DB, et al. J Am Coll Cardiol. 2020;76(16):1905-1909.

234 8. Maddaus M. Ann Thorac Surg. 2020;109(1):18-25. 
Table 1 - Criteria for the Certificate of da Vinci ${ }^{\circledR}$ System Training for Residents and Fellows 


\begin{tabular}{|c|c|c|}
\hline Name & Institution & Link \\
\hline \multicolumn{3}{|l|}{ Fellowships } \\
\hline $\begin{array}{l}\text { STS/TSF Advanced Robotic Cardiac } \\
\text { Surgery Fellowship }\end{array}$ & $\begin{array}{l}\text { Society of Thoracic Surgeons } \\
\text { The Thoracic Surgery Foundation }\end{array}$ & $\begin{array}{l}\text { https://thoracicsurgeryfoundation.org/roboticcard } \\
\text { iacfellowship/ }\end{array}$ \\
\hline $\begin{array}{l}\text { AATS Foundation Cardiac Surgical } \\
\text { Robotic Fellowship }\end{array}$ & $\begin{array}{l}\text { Cleveland Clinic, Emory University at Midtown, } \\
\text { New York University, West Virginia University, } \\
\text { Mayo Clinic }\end{array}$ & $\begin{array}{l}\text { https://www.aats.org/aatsimis/AATSWeb/Foundati } \\
\text { on/Programs/Programs/Cardiac Surgical Robotics } \\
\text { Program/Cardiac Surgical Robotics Program.asp } \\
\text { x }\end{array}$ \\
\hline $\begin{array}{l}\text { Advanced Robotic Cardiac Surgery } \\
\text { Fellowship }\end{array}$ & $\begin{array}{l}\text { Division of Cardiothoracic Surgery, Emory } \\
\text { University School of Medicine, GA, USA }\end{array}$ & $\begin{array}{l}\text { http://www.surgery.emory.edu/training/ct- } \\
\text { surgery-residency-fellowships/advanced-robotic- } \\
\text { cardiac-surgery-fellowship.html }\end{array}$ \\
\hline $\begin{array}{l}\text { Minimally Invasive CT Surgery } \\
\text { Fellowship }\end{array}$ & $\begin{array}{l}\text { Department of Cardiovascular and Thoracic } \\
\text { Surgery, West Virginia University, WV, USA }\end{array}$ & $\begin{array}{l}\text { https://medicine.hsc.wvu.edu/cardiovascular-and- } \\
\text { thoracic-surgery/fellowships/cardiothoracic- } \\
\text { surgery-residency/minimally-invasive-ct-surgery- } \\
\text { fellowship/ }\end{array}$ \\
\hline Resident Robotic Surgery Training & $\begin{array}{l}\text { Department of Cardiothoracic Surgery, Weill } \\
\text { Cornell Medicine, NY, USA }\end{array}$ & $\begin{array}{l}\text { https://ctsurgery.weillcornell.org/education/reside } \\
\text { nt-robotic-surgery-training }\end{array}$ \\
\hline \multicolumn{3}{|l|}{ Training courses } \\
\hline $\begin{array}{l}\text { STS Workshop on Robotic Cardiac } \\
\text { Surgery }\end{array}$ & Society of Thoracic Surgeons (Annual event) & $\begin{array}{l}\text { https://www.sts.org/meetings/live-courses/2020- } \\
\text { sts-workshop-robotic-cardiac-surgery-agenda }\end{array}$ \\
\hline $\begin{array}{l}\text { Robotic Training Courses at ORSI } \\
\text { Academy }\end{array}$ & ORSI Academy, Belgium & https://www.orsi-online.com/en/training \\
\hline IRCAD 2 & University Hospital of Strasbourg & https://www.ircad.fr/inauguration-de-lircad-2-2/ \\
\hline $\begin{array}{l}\text { Robotic Academy Intuitive Naples } \\
\text { (RAIN) }\end{array}$ & $\begin{array}{l}\text { GRIO Inter Hospital Robotic Group (Antonio } \\
\text { Cardarelli Hospital, Naples, Italy) }\end{array}$ & http://www.centrodibiotecnologie.org/en/rain/ \\
\hline \begin{tabular}{|l|} 
RPA Surgical \& Robotic Training \\
Institute
\end{tabular} & Royal Prince Alfred Hospital, Sydney, Australia & $\begin{array}{l}\text { https://www.slhd.nsw.gov.au/rpa/robotic/about.ht } \\
\text { ml }\end{array}$ \\
\hline (ICRS) Robotic Surgery course & $\begin{array}{l}\text { International College of Robotic Surgeons, World } \\
\text { Laparoscopy Hospital }\end{array}$ & $\begin{array}{l}\text { https://www.laparoscopyhospital.com/roboticsurg } \\
\text { erytraining.html }\end{array}$ \\
\hline
\end{tabular}

Table 2 - Currently available robotic fellowships and specialization courses. Accessed July 18th, 2021 
1. Master cardiac surgery first, then learn robotic cardiac surgery.

2. Keep training on simulators even when you think you have gained enough confidence.

3. Spend some time in the operating room of robotic surgeons in different specialties.

4. Build your own video library of robotic cases, review it frequently with a critical eye.

5. Strive to maintain your open skills.

6. Find the right mentor(s), and make sure you are the right mentee.

7. Develop strong mental skills.

8. Build a resilient attitude and a good work-life balance.

9. Be ready to change quickly and enjoy the process.

10. Keep reminding yourself of what your driving force is.

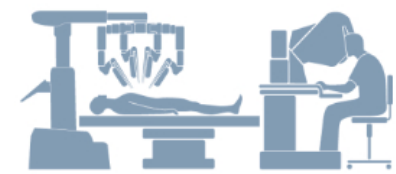

Figure 1 - Tips to building a successful career in robotic cardiac surgery. $159 \times 74 \mathrm{~mm}(144 \times 144$ DPI $)$ 